\title{
Comparative evaluation of abdominal hysterectomy by ligasure and conventional method
}

\section{Harjinder Singh, Monika Jindal*, Monika Gupta, S. P. S. Goraya, Manisha Behal, Tanjeet}

Department of Obstetrics and Gynecology, Maharishi Markandeshwar Medical College and Hospital, Kumarhatti, Himachal Pradesh, India

Received: 14 October 2017

Accepted: 08 November 2017

\section{*Correspondence:}

Dr. Monika Jindal,

E-mail: monikajindal@rocketmail.com

Copyright: (c) the author(s), publisher and licensee Medip Academy. This is an open-access article distributed under the terms of the Creative Commons Attribution Non-Commercial License, which permits unrestricted non-commercial use, distribution, and reproduction in any medium, provided the original work is properly cited.

\begin{abstract}
Background: Hysterectomy is the $2^{\text {nd }}$ most common surgical procedure performed in women and is associated with various complications like any other major surgical procedure. The objectives and aims of this study was to compare the effects of ligasure and conventional clamping and suturing in abdominal hysterectomy.

Methods: A randomized controlled trial was performed by randomizing the patients in 2 groups - ligasure (A) and conventional hysterectomy (B). Operative time, no. of sutures, blood loss, hospital stay and cost factor to patient were studied as its main outcomes. A total of 100 patients were studied.

Results: $66 \%$ of patients in group A had duration of surgery that was less than an hour in spite of associated comorbidities. More no (76\%) of patients in Group A had significantly less blood loss $(<50 \mathrm{ml})$ as compared to $60 \%$ of patients in Group B. Only one suture was used in $80 \%$ of patients in Group A while in group B all of the patients required more than one suture from stumps to vault. There by reducing the cost of surgery.

Conclusion: Apparently ligasure group seems to have less time for surgery and less blood loss and more intraoperative and postoperative complications, but to prove one ligasure group superior or inferior over conventional method we need to have more studies. But yes, Ligasure group reduces the cost of surgery to patient by reducing suture consumption as compared to conventional group.
\end{abstract}

Keywords: Blood loss, Conventional, Ligasure, Hysterectomy, Suture

\section{INTRODUCTION}

Hysterectomy is the second most frequently performed major surgical procedures on women all over the world, next to caesarean. In US, approximately 600,000 hysterectomies are performed each year. ${ }^{1}$ In India no national statistics for hysterectomy is available. A study conducted in northern state of India (Haryana) states that incidence was $7 \%$ among married women above 15 years of age. ${ }^{2}$ Another study from a Western state (Gujarat) pointed out that $7-8 \%$ of rural and $5 \%$ of urban women had already undergone hysterectomy at an average age of 37 years. ${ }^{3}$ Indications of hysterectomy vary from benign condition to malignancies of genital tract. Term "hysterectomy" though means removal of uterus, in practice it has a much wider classification depending upon the indication. At times it is done without removal of the cervix (supracervical hysterectomy) or with removal of adnexa (hysterectomy with salpingooophorectomy). It can also be a part of staging laparotomy or radical hysterectomy. Hysterectomy can be performed abdominally, vaginally or through abdominal ports with help of a laparoscope. Approach depends on surgeon's preference, indication for surgery, nature of disease, and patient characteristics. ${ }^{4}$ Abdominal hysterectomy has the advantage of good intra-operative field, but the disadvantages are an abdominal wall scar and the long time for recovery. ${ }^{5,6}$ 
As any other surgery, hysterectomy is also associated with intraoperative and postoperative complications. Rates of various complications with hysterectomy have been reported in the range from $0.5 \%$ to $43 \%{ }^{7}$

Emergence of effective medical and conservative treatment for benign conditions in the uterus is now posing a question mark regarding the justification of hysterectomy. It has been realized that uterus should not be considered as a vestigial organ after child bearing. Studies have proved that following hysterectomy women suffer with bothersome psychosexual functions and increased incidence of vaginal prolapse due to deficiency of supporting ligaments. ${ }^{8}$ It has also been hypothesized that ovarian endocrinal function weans off more rapidly after removal of their target organ. Mean age of onset of menopause in those who underwent hysterectomy is 3.7 years earlier than average, even when the ovaries are preserved. ${ }^{9}$

In India, every year quite a large number of abdominal hysterectomies are performed. Most of these operations are performed for benign conditions causing menorrhagia, metrorrhagia, dysmenorrhea, or pelvic pain like AUB, fibroid uterus and ovarian cysts.

Vascular pedicles during hysterectomy can be secured using usual mechanical ways (sutures, clips or staples), or by vessel coagulation (high frequency electrocautery, ultrasound or laser). ${ }^{10,11}$ To replace the usual methods of haemostasis, the ligasure vessel sealing apparatus was launched by Valleylab (Boulder, CO, USA). ${ }^{12,13}$ It is operated by recognizing the type of tissue to pass the right dose of pressure and energy. This dose alters the collagen and elastin in the vessels to be sealed with minimal lateral thermal injury. ${ }^{11-13}$

Ligasure is becoming more popular in many operative procedures as thyroidectomy, hysterectomy, splenectomy, and urology procedures. $^{12}$ It is more suitable for difficult operative cases because it can abandon the need for vessel traction and the shorter time needed for haemostasis. ${ }^{5,10,14}$ The efficacy of ligasure in gynaecological procedures was found to be comparable to clips and ultrasonic vessel sealing. The Ligasure Vessel Sealing System (LVSS) was developed for sealing vessels and tissue bundles up to $7 \mathrm{~mm}$ in diameter by using a controlled high-power current at low voltage to melt the tissue's collagen and elastin. This technique is associated with reduced thermal spread in comparison with unipolar cautery. ${ }^{14}$ LVSS is relatively faster compared with suture ligation as the current delivered to achieve haemostasis takes between 2 and 7 seconds. $^{5}$

The purpose of the current study is to compare the efficiency of ligasure vessel sealing system with conventional sutures ligation method in abdominal hysterectomy using different parameters: the operating time, operative blood loss, number of sutures used, haemoglobin level, the hospitalization, and the intraoperative and immediate postoperative complications.

The aims and objectives of this study were:

- To study and compare the abdominal hysterectomy by ligasure and conventional method by clamping and ligating ligaments

- To compare time taken for surgery, intraoperative bleeding, number of sutures needed to secure stumps and vault

- To compare the cost of suture material used in both the groups

- To compare postoperative complications, duration of hospital stays in both the groups.

\section{METHODS}

Total 100 patients were studied and were randomly distributed as 50 in each group: Group A who were hysterectomized by using ligasure and group B who were hysterectomized by conventional method.

Patients in both the groups were studied and compared as per the given Performa. Intraoperative blood loss was calculated by measuring blood on sterile drapes, and by evaluating the blood in abdominal swabs and gauzes.

Cost of the suture used was studied in both the groups for stump securing and vault closure. To remove the bias Polyglactin no. 1 (maximum of 3) was used to secure pedicles in Group B and SIMILAR sutures were used in both the groups for rest of the procedure.

\section{Exclusion criteria}

- Immunocompromised state eg. HIV, TB.

- Uncontrolled DM.

- Preoperative Fever.

- Anemic patients having $\mathrm{Hb}<8 \mathrm{gm} \%$.

\section{RESULTS}

Maximum patients in both the groups were from age group of 45 and above. Hysterectomy was done at the young age of $35 \mathrm{yrs}$ in one patient as she was mentally retarded and was not able to handle her menses. One patient had grade 4 endometriosis and had secondary spasmodic dysmenorrhoea that was not relieved by medication.

Table 1: Distribution of patients according to age in both Groups.

\begin{tabular}{|lll|}
\hline Age (years) & Group A & Group B \\
\hline $30-35$ & $1^{*}$ & 0 \\
\hline $36-40$ & $1^{* *}$ & 1 \\
\hline $41-45$ & 17 & 20 \\
\hline$>45$ & 31 & 29 \\
\hline Total & 50 & 50 \\
\hline
\end{tabular}


Associated co-morbidities were more in ligasure group (Group A) in the form of hypertension, obesity, DM, UTI, hypothyroidism, anaemia (HB >8, <11) and heart disease in $2 \%$ cases.

Table 2: Associated co-morbidities in both the groups.

\begin{tabular}{|ll|l|}
\hline Co-morbidity & Group A & Group B \\
\hline Hypertension & 5 & 4 \\
\hline Obesity & 3 & 1 \\
\hline Diabetes & 4 & 1 \\
\hline UTI & 3 & 1 \\
\hline Hypothyroidism & 1 & 1 \\
\hline Anaemia & 4 & 1 \\
\hline Heart disease & 1 & 0 \\
\hline None & 29 & 41 \\
\hline
\end{tabular}

Maximum patients in both the groups had tubal ligation as previous surgical procedure, only $13 \%$ patients were for primary surgery.

Table 3: History of prior surgery.

\begin{tabular}{|lll|}
\hline Prior surgery & Group A & Group B \\
\hline Tubal ligation & 40 & 34 \\
\hline Laparotomy & 1 & 4 \\
\hline LSCS & 2 & 6 \\
\hline None & 7 & 6 \\
\hline
\end{tabular}

Most common indication for hysterectomy in both the groups was AUB.

Table 4: Indication of hysterectomy in both the groups.

\begin{tabular}{|lll|}
\hline Indication of Hysterectomy & Group A & Group B \\
\hline AUB & 23 & 26 \\
\hline Adenexal pathology & 3 & 1 \\
\hline Chronic PID & 5 & 2 \\
\hline PMB & 4 & 3 \\
\hline Endo-hyperplasia & 2 & 6 \\
\hline Fibroid & 13 & 12 \\
\hline
\end{tabular}

$66 \%$ of patients in group A had duration of surgery that was less than an hour in spite of associated comorbidities. Co-morbidities were found in $42 \%$ patients in group A and in only 18\% patients of Group B. $37 \%$ patients had surgery duration of up to 2 hours.

Table 5: Duration of surgery.

\begin{tabular}{|lll|}
\hline $\begin{array}{l}\text { Duration of surgery } \\
\text { (in minutes) }\end{array}$ & Group (A) & Group (B) \\
\hline$<60$ minutes & 33 & 30 \\
\hline $60-120$ minutes & 17 & 20 \\
\hline
\end{tabular}

There was no significant difference in hospital stay in both the groups. Patients who had subcutaneous sutures had shorter hospital stay.
Table 6: No. of hospitalisation days in postoperative period.

\begin{tabular}{lll}
$\begin{array}{l}\text { No of hospital days in postop } \\
\text { period }\end{array}$ & Group A & Group B \\
\hline$<6$ days & 17 & 20 \\
\hline$>6$ days & 33 & 30 \\
\hline
\end{tabular}

Bladder injury was seen in 1 case in Group A that was attributed to difficulty in surgery due to dense adhesions attributed to prior surgeries and slippage of ligature was seen in 1 patient in group B.

Table 7: Intraop complications.

\begin{tabular}{|lll|}
\hline Intra-op complications & Group A & Group B \\
\hline Bladder injury & 1 & 0 \\
\hline Slippage of ligature & 0 & 1 \\
\hline
\end{tabular}

More no. (76\%) of patients in Group A had significantly less blood loss $(<50 \mathrm{ml})$ as compared to $60 \%$ of patients in Group B and not a single patient required intraoperative or postoperative blood transfusion in Group A.

Table 8: Intra-op blood loss.

\begin{tabular}{|lll|}
\hline Intra-op blood loss $(\mathrm{ml})$ & Group A & Group B \\
\hline $30-50 \mathrm{ml}$ & 38 & 30 \\
\hline $50-100 \mathrm{ml}$ & 12 & 20 \\
\hline
\end{tabular}

Only one suture was used in $80 \%$ of patients in Group A while in group B all of the patients required more than one suture from stumps till vault. There by reducing the cost of surgery.

Table 9: No. of sutures used.

\begin{tabular}{|c|c|c|}
\hline No of sutures used & Group A & Group B \\
\hline 1 & 40 & 0 \\
\hline 2 & 10 & 35 \\
\hline$\geq 3$ & 0 & 15 \\
\hline
\end{tabular}

Complications were apparently more in Group A, but wound dehiscence was only superficial that cannot be attributed to ligasure and same with the bladder injury and subsequent VVF. That was due to dense adhesions. Fever was of low grade that settled in 24 hours.

Table 10: Postoperative complications.

\begin{tabular}{|lll|}
\hline Postop complications & Group A & Group B \\
\hline Fever & 5 & 1 \\
\hline Frequency of micturition & 1 & 2 \\
\hline Pain abdomen & 3 & 3 \\
\hline Wound dehiscence* & 6 & 1 \\
\hline Vvf & 1 & 0 \\
\hline Bleeding pv & 1 & 1 \\
\hline None & 33 & 42 \\
\hline
\end{tabular}




\section{DISCUSSION}

Maximum patients in both the groups were from age group of 45 and above. Hysterectomy was done at the young age of 35 years in one patient as she was mentally retarded and was not able to handle her menses. One patient had grade 4 endometriosis and had secondary spasmodic dysmenorrhea that was not relieved by medication.

Associated co-morbidities were more in ligasure group (Group A). Most common indication for hysterectomy in both the groups was AUB. In a study done by Pandey D et al, they found that most common indication for hysterectomy was symptomatic fibroid uterus along with DUB $(39.1 \%$ and $8.9 \%){ }^{4}$

$66 \%$ of patients in group A had duration of surgery that was less than an hour in spite of associated comorbidities. Co-morbidities were found in $42 \%$ patients in group A and in only $18 \%$ patients of Group B. There was no significant difference in hospital stay in both the groups.

Bladder injury was seen in 1 case in Group A that was attributed to dense adhesions due to prior surgeries and slippage of ligature was seen in 1 patient in group B. Incidence of bladder injury was same as in Lakeman et al study. ${ }^{15}$ Foley's catheter drainage was done in VVF cases for 4 weeks and healed spontaneously. No surgical intervention was required.

More no $(76 \%)$ of patients in Group A had significantly less blood loss $(<50 \mathrm{ml})$ as compared to $60 \%$ of patients in Group B and not a single patient required intraoperative or postoperative blood transfusion in Group A.

Only one suture was used in $80 \%$ of patients in Group A while in group B all of the patients required more than one suture from stumps to vault. There by reducing the cost of surgery. Complications were apparently more in Group A, but wound dehiscence was only superficial that cannot be attributed to ligasure and same with the VVF. VVF was present in patient with difficult surgery due to dense adhesions. Fever was of low grade that got settled in 24 hours.

In a similar study done by Lakeman et al the amount of blood loss, surgery time, complication risk and duration of hospitalization were similar between both groups. ${ }^{15}$

\section{CONCLUSION}

Apparently ligasure group seems to have less time for surgery and less blood loss and more intraoperative and postoperative complications, but to prove one ligasure group superior or inferior over conventional method we need to have more studies. But yes Ligasure group reduces the cost of surgery to patient by reducing suture consumption as compared to conventional group.

\section{ACKNOWLEDGMENTS}

Authors would like to express their sincere gratitude to their patients who showed faith in them and opted for participation in this study.

Funding: No funding sources

Conflict of interest: None declared

Ethical approval: The study was approved by the Institutional Ethics Committee

\section{REFERENCES}

1. Wu JM, Wechter ME, Geller EJ, Nguyen TV, Visco AG. Hysterectomy rates in the United States, 2003. Obstet Gynecol. 2007;110(5):1091-5.

2. Singh A, Arora AK. Why hysterectomy rate is lower in India. Indian J Community Med. 2008 ;33(3):196.

3. Desai S, Sinha T, Mahal A. Prevalence of hysterectomy among rural and urban women with and without health insurance in Gujarat, India. Reproductive Health Matters. 2011;19(37):42-51.

4. Pandey D, Sehgal K, Saxena A, Hebbar S, Nambiar J, Bhat RG. An audit of indications, complications, and justification of hysterectomies at a teaching hospital in India. Int J Reprod Med. 2014;2014.

5. Hefni MA, Bhaumik J, El-Toukhy T, Kho P, Wong I, Abdel-Razik T, et al. Safety and efficacy of using the LigaSure vessel sealing system for securing the pedicles in vaginal hysterectomy: randomised controlled trial. Int $\mathbf{J}$ Obstet Gynaecol. 2005;112(3):329-33.

6. Zubke W, Hornung R, Wässerer S, Hucke J, Füllers $\mathrm{U}$, Werner C, et al. Bipolar coagulation with the BiClamp ${ }^{\circledR}$ forceps versus conventional suture ligation: a multicenter randomized controlled trial in 175 vaginal hysterectomy patients. Arch Gynecol Obstet. 2009;280(5):753-60.

7. Lee NC, Dicker RC, Rubin GL, Ory HW. Confirmation of the preoperative diagnoses for hysterectomy. Am J Obstet Gynecol. 1984;150(3):283-7.

8. McPherson K, Herbert A, Judge A, Clarke A, Bridgman S, Maresh M, et al. Psychosexual health 5 years after hysterectomy: population-based comparison with endometrial ablation for dysfunctional uterine bleeding. Health Expectations. 2005;8(3):234-43.

9. Farquhar CM, Sadler L, Harvey SA, Stewart AW. The association of hysterectomy and menopause: a prospective cohort study. Int J Obstet Gynaecol. 2005;112(7):956-62.

10. Gizzo S, Burul G, Di Gangi S, Lamparelli L, Saccardi C, Nardelli GB, et al. LigaSure vessel sealing system in vaginal hysterectomy: safety, efficacy and limitations. Arch Gynecold Obstet. 2013;288(5):1067-74. 
11. Janssen PF, Brölmann HA, van Kesteren PJ, Bongers MY, Thurkow AL, Heymans MW, et al. Perioperative outcomes using LigaSure ${ }^{\mathrm{TM}}$ compared to conventional bipolar instruments in laparoscopic salpingo-oophorectomy: a randomized controlled trial. Surgical Endoscopy. 2012;26(10):2884-91.

12. Ding Z, Wable M, Rane A. Use of LigaSure ${ }^{\mathrm{TM}}$ bipolar diathermy system in vaginal hysterectomy. J Obstet Gynaecol. 2005;25(1):49-51.

13. Hagen B, Eriksson N, Sundset M. Randomised controlled trial of LigaSure versus conventional suture ligature for abdominal hysterectomy. Int J Obstet Gynaecol. 2005;112(7):968-70.

14. Levy B, Emery L. Randomized trial of suture versus electrosurgical bipolar vessel sealing in vaginal hysterectomy. Obstet Gynecol. 2003;102(1):147-51.
15. Lakeman M, Kruitwagen RF, Vos MC, Roovers JP. Electrosurgical bipolar vessel sealing versus conventional clamping and suturing for total abdominal hysterectomy: a randomized trial. J Minimally Invasive Gynecol. 2008;15(5):547-53.

Cite this article as: Singh $\mathrm{H}$, Jindal M, Gupta M, Goraya SPS, Behal M, Tanjeet. Comparative evaluation of abdominal hysterectomy by ligasure and conventional method. Int J Reprod Contracept Obstet Gynecol 2017;6:5587-91. 